\title{
Development and evaluation of a gold nanoparticle-based immunochromatographic strip test for the detection of canine parvovirus
}

\author{
Chhavi Sharma ${ }^{1} \cdot$ Mithilesh Singh $^{1} \cdot$ Vikramaditya Upmanyu $^{2} \cdot$ Vishal Chander $^{3} \cdot$ Suman Verma $^{1}$. \\ Soumendu Chakrovarty ${ }^{4} \cdot$ Gaurav K. Sharma $^{3} \cdot$ Himani Dhanze $^{5}$. Praveen Singh ${ }^{6} \cdot$ Sameer Shrivastava $^{7}$. \\ Jyoti Kumar ${ }^{1} \cdot$ Tapas Kumar Goswami $^{1}$ • V. K. Gupta ${ }^{3}$
}

Received: 24 January 2018 / Accepted: 12 April 2018 / Published online: 8 May 2018

(c) Springer-Verlag GmbH Austria, part of Springer Nature 2018

\begin{abstract}
Canine parvovirus (CPV) is the leading viral cause of enteritis in dogs and occurs mainly in 6- to 8-week-old pups. Rapid diagnosis of CPV under field conditions is now possible due to commercially available immunochromatographic (IC) assays. However, these commercial kits are somewhat expensive because they utilize a minimum of two monoclonal antibodies (mAbs) targeting different epitopes as capture and detector antibodies. Using only a single mAb for both capture and detection purpose may reduce the sensitivity of the assay. In the present study, efforts were made to develop an economical assay that can be utilized for diagnosis of CPV under Indian conditions with a high level of confidence. Rabbit polyclonal antibodies (pAbs) generated against recombinant truncated VP2 proteins of CPV were used as capture antibodies because they can be produced economically, while a commercial anti-CPV mAb was used as the detector antibody. The detection limit of the test strip was $6.6 \times 10^{5} \mathrm{TCID}_{50} \mathrm{ml}$, and it specifically detected CPV-2, CPV-2a and CPV-2b while displaying no cross-reactivity with other common canine enteric pathogens. The relative sensitivity/specificity of pAb based strip test was $71 \% / 92 \%$ and $71 \% / 100 \%$ in relation to the hemagglutination test and a commercial IC kit, respectively, with substantial agreement. In addition, two commercially available mAbs targeting different epitopes were also used for development of another IC assay, which showed sensitivity, and specificity of $82 \% / 87 \%$ and $90 \% / 98 \%$ in relation to the hemagglutination test and commercial kit. Hence, the present strip test based on a combination of $\mathrm{mAb}$ and $\mathrm{pAb}$ provides an acceptable alternative for onsite and cost-effective diagnosis of CPV infection.
\end{abstract}

\section{Introduction}

Handling Editor: Ayato Takada.

Mithilesh Singh

drmithileshsingh@yahoo.com

Immunology Section, IVRI, Izatnagar 243122, UP, India

2 Department of Biological Standardization, IVRI, Izatnagar, India

3 CADRAD, IVRI, Izatnagar, India

4 Department of Biological Products, IVRI, Izatnagar, India

5 Department of Veterinary Public Health, IVRI, Izatnagar, India

6 Biophysics and Electron Microscopy Section, IVRI, Izatnagar, India

7 Department of Veterinary Biotechnology, IVRI, Izatnagar, India
Canine parvoviral enteritis is a highly contagious and fatal viral disease that is responsible for neonatal death in pups [1, 2]. The etiological agent, canine parvovirus $2(\mathrm{CPV}-2)$, is a small, non-enveloped, negative-sense ss-DNA virus with a genome of $5.2 \mathrm{~kb}$ in length that encodes two non-structural (NS1 and NS2) and two structural (VP1 and VP2) proteins [3]. VP2 is the major capsid protein, which plays a crucial role in determining antigenicity, host range and tissue tropism [4]. This virus, which initially emerged in 1970s and spread globally thereafter, is now considered endemic in the dog population, with the existence of different antigenic variants, viz., CPV-2a, CPV-2b, CPV-2c, new CPV-2a/2b [5-7].

Due to the acute and highly contagious nature of the disease, an early and prompt diagnosis is essential in order to adopt biosecurity measures for preventing the spread of the disease to the susceptible population, and 
also to initiate supportive treatment to reduce morbidity and mortality. Hence, a simple, cost-effective, field-based test is essential for rapid diagnosis of canine parvoviral enteritis. Several diagnostic assays have been developed for the detection of CPV; however, each of these assays has its own merits and demerits in terms of cost, sensitivity, specificity and convenience that may render them unsuitable for widespread field use [8]. The diagnostic assays frequently employed for the detection of CPV-2 are hemagglutination (HA) test, virus isolation, enzymelinked immunosorbent assay (ELISA; SNAP Parvo, Idexx USA) and polymerase chain reaction (PCR).

A range of commercial immunochromatographic (IC)-strip-based assays are available for rapid detection of CPV-2 under field conditions $[9,10]$. Most of these kits are not produced in India and must be imported from other countries, which increases the cost per test. These strip tests are based on the sandwich principle, using either a single monoclonal antibody (mAb) or two different CPV-specific mAbs as detector and capture antibodies. Although not described in the literature, the use of the same mAb for both capture and detection in these IC assays may limit the sensitivity of detection in cases of low fecal CPV load, as the capture and detector mAbs would compete for the same epitope. This could be the reason behind the poor sensitivity displayed by these assays, especially during late stage of the infection, when fecal shedding is significantly reduced $[9,11]$. Alternatively, employing two different mAbs in these strip-based assays is an expensive proposition, limiting its practical usability on a wider scale. Furthermore, binding of one $\mathrm{mAb}$ (detector) to an epitope has the potential of affecting certain other spatially unrelated epitopes in a way that could alter the binding of the second $\mathrm{mAb}$ [12]. Utilizing a polyclonal antibody $(\mathrm{pAb})$ instead of an $\mathrm{mAb}$ as the capture antibody in the IC test may hold promise, as using mAbs as detector antibodies may result in alteration of only some of the original epitopes, leaving the rest of the epitopes unaltered and accessible to the polyclonal capture antibodies. Furthermore, pAbs are generally less expensive and faster to produce than mAbs.

Considering the importance of developing an indigenous and economical kit that utilizes homemade biological reagents, the present study was undertaken to explore the combination of an $\mathrm{mAb}$ and $\mathrm{pAbs}$ as detector and capture antibodies, respectively, for the development of an IC test for rapid detection of CPV. Furthermore, for economical production of pAbs in the laboratory, recombinant structural proteins of CPV were expressed in truncated form for higher yield using a prokaryotic system. The use of recombinant proteins eliminates the risk of handling live virus in the laboratory for production of pAbs.

\section{Materials and methods}

\section{Clinical samples}

A total of 97 fecal swabs $(n=97)$, collected in duplicate from dogs of different age groups (both vaccinated and unvaccinated) showing symptoms of gastroenteritis were collected from the Referral Veterinary Polyclinic located at the Indian Veterinary Research Institute, Izatnagar Bareilly, UP, India, during the years 2015 and 2016 and processed as described earlier [13]. The clinical samples were tested for the presence of CPV using a hemagglutination (HA) test (HA titers $\geq 32$ were considered positive for CPV) and a commercially available IC-based Rapid CPV Ag Test Kit (Bionote, Republic of Korea).

\section{Cloning, bacterial expression, and purification of truncated CPV VP2 proteins (CPV-tVP2)}

Two overlapping fragments corresponding to the N-terminal end and most of the C-terminal end of the VP2 gene were targeted separately for amplification (N-region, $\mathrm{nt}$ 10-770; C-region, nt 750-1641) using genomic DNA from cell-culture-adapted CPV-2a (BE-1; NCBI GenBank accession number KJ364524). The primers CPVNF (5-ACACAGAATTCAGGAGCAGTTCAACCAGA C-3) and CPV-NR (5-ATCTAGATTCTCGAGTGTTCC TGTAGCAAATTCATC-3) were used for amplification of the N-terminal region, and the primers CPV-CF (5-ACT GCAGCGAATTCAGGTGATGAATTTGCTACAG-3) and CPV-CR (5-GGGCTCGAGTGGATTCCAAGTATGAGA G-3) were used for amplification of the partial C-terminal region. The resulting PCR products were gel purified, ligated with $\mathrm{pET} 32 \mathrm{~b}$ vector, and used to transform chemically competent $E$. coli BL21 strain Rosetta (DE3) pLysS cells (Novagen, Germany) following standard procedures. Expression of recombinant CPV-tVP2 protein was optimized by evaluating the different combinations of IPTG concentration, temperature, and time for induction, as described earlier [14]. A overnight-grown bacterial culture was harvested by centrifugation and lysed in a buffer containing $8 \mathrm{M}$ urea, $100 \mathrm{mM} \mathrm{NaH}{ }_{2} \mathrm{PO}_{4}$ and $10 \mathrm{mM}$ Tris. $\mathrm{Cl}$, $\mathrm{pH}$ 8.0, prior to sonication. Both recombinant CPV-tVP2 proteins were purified by affinity chromatography using Ni-NTA resin (QIAGEN, Inc., Hilden, Germany) under denaturing conditions as described by the manufacturer. The purified CPV-tVP2 proteins were electro-transferred onto the nitrocellulose membrane (MDI, India) in order to test their immunoreactivity by Western blotting. The membrane was probed with a known anti-CPV dog serum (1:100 dilution) collected from healthy vaccinated dogs, 
and following incubation with anti-dog HRPO conjugate, the proteins on the membrane were detected using an enzymatic reaction.

\section{Generation of anti-CPV-tVP2 rabbit pAbs}

Two healthy young male New Zealand white rabbits were injected intramuscularly with a mixture of $100 \mu \mathrm{g}$ of each of the purified recombinant CPV-tVP2 proteins mixed in equal proportion with Freund's complete adjuvant (Sigma, USA). Rabbits were boosted three times at an interval of two weeks each with same antigen mixed with Freund incomplete adjuvant (Sigma, USA). Serum was harvested after bleeding the animals on the tenth day following the last injection. Blood serum was collected and reactivity was determined by dot-blot assay using CPV-tVP2 protein and A-72 infected CPV as per the standard procedure. The total immunoglobulin $\mathrm{G}(\mathrm{IgG})$ from the CPV-tVP2 specific rabbit hyperimmune serum was separated using a protein A affinity column (Thermo Scientific, USA) following the procedure described by the manufacturer. The purified rabbit IgG fraction was quantified using a spectrophotometer and stored at $-80{ }^{\circ} \mathrm{C}$ for subsequent use.

\section{Preparation of colloidal gold nanoparticle conjugate}

\section{Determination of the optimum $\mathrm{pH}$ and antibody concentration for gold conjugation}

The CPV-specific mAb (Thermo Scientific, USA) was conjugated to 30-nm colloidal gold nanoparticles (GNPs) (Sigma, USA) under various conditions of $\mathrm{pH}$ and antibody concentration using $\mathrm{NaCl}$ flocculation assay and UV-Vis absorbance assay as described earlier $[15,16]$ with slight modifications. Briefly, the $\mathrm{pH}$ of $100 \mu \mathrm{l}$ of GNPs was adjusted from 6 to 9 in a microtiter plate in increments of 0.5 by adding $0.1 \mathrm{~N}$ $\mathrm{K}_{2} \mathrm{CO}_{3}$ and testing the $\mathrm{pH}$ with Hi-media $\mathrm{pH}$ indicator strips (Hi-media, India). Anti CPV mAb $(1 \mathrm{mg} / \mathrm{ml})$ at different concentrations $(0,5,10,20$ and $30 \mu \mathrm{g} / \mathrm{ml})$ was added to each well containing GNPs at different $\mathrm{pH}$ values. The mixtures were allowed to react for $15 \mathrm{~min}$ at room temperature with manual shaking, and $20 \mu \mathrm{l}$ of $10 \% \mathrm{NaCl}$ was then added to each well, and gentle shaking was continued for another $15 \mathrm{~min}$. The solution was monitored visually for any color change (GNPs flocculation) and absorbance was measured using a microplate reader (Thermo Scientific, USA) at 580 $\mathrm{nm}$ and $600 \mathrm{~nm}$ to calculate the stability index $\left(\mathrm{SI}=\mathrm{OD}_{\lambda \max } /\right.$ $\left.\mathrm{OD}_{580}\right)$ and polydispersity index $\left(\mathrm{PI}=\mathrm{OD}_{600} / \mathrm{OD}_{\lambda \max }\right)$. Average values were calculated from three repeated experiments. The optimal coverage of colloidal gold with mAbs was further verified by UV-Vis spectrophotometery, differential light scattering (DLS), transmission electron microscopy (TEM), and dot-blot assay, using standard method.

\section{Preparation of $\mathrm{mAb}$-colloidal gold conjugate}

Briefly, $1 \mathrm{~mL}$ of colloidal gold suspension was adjusted to the optimized $\mathrm{pH}$ using $0.1 \mathrm{~N} \mathrm{~K}_{2} \mathrm{CO}_{3}$ and the optimal amount of anti-CPV mAb was then added with constant stirring. The adsorption of mAbs on the surface of the GNPs was allowed to take place at room temperature with constant stirring for $30 \mathrm{~min}$. Unreactive sites on GNPs were blocked by addition of $0.01 \mathrm{M}$ PBS, $\mathrm{pH} 7.2$, containing $10 \%$ bovine serum albumin (BSA) at room temperature with continuous stirring for $15 \mathrm{~min}$. The solution was centrifuged at 8000 rpm for $30 \mathrm{~min}$ at $4{ }^{\circ} \mathrm{C}$, and the soft pellet was washed with $0.01 \mathrm{M}$ PBS, $\mathrm{pH} 7.2$, with centrifugation at $8000 \mathrm{rpm}$ for 30 min at $4{ }^{\circ} \mathrm{C}$ to remove unbound antibodies from the solution. Finally, the pellet was resuspended with one tenth of the original volume in $0.01 \mathrm{M} \mathrm{PBS}, \mathrm{pH} 7.2$, containing $1 \%$ BSA and subsequently stored at $4{ }^{\circ} \mathrm{C}$ for future use.

\section{Preparation of an $\mathrm{mAb} / \mathrm{pAb}$-based lateral flow immunochromatographic test strip}

The colloidal gold conjugate was coated onto the conjugate pad (MDI, India) by manual pipetting ( $10 \mu \mathrm{l}$ of conjugate per strip) and allowed to air dry. A nitrocellulose membrane (MDI, India) was charged with test and control antibodies by manual pipetting or using an Easy Printer (MDI, India). Different concentrations $(1,2$ and $5 \mathrm{mg} / \mathrm{ml})$ of anti-CPV-tVP2 rabbit polyclonal IgG and goat anti-mouse pAbs (Genei, India) were used for coating on the test and control line, respectively. After coating, the membrane was air dried at $37{ }^{\circ} \mathrm{C}$ for $2 \mathrm{~h}$ and then assembled with other pads. The distance between test and control line was kept at around $5 \mathrm{~mm}$. Other variables that could potentially influence the performance of the IC test were also optimized, and these are presented in Table 1.

Table 1 Optimization of IC test with minor variables

\begin{tabular}{|c|c|}
\hline Variables & Optimum \\
\hline $\begin{array}{l}\text { Membrane pore size }(5,8 \text { and } 10 \\
\mu \mathrm{m})\end{array}$ & 8 and $10 \mu \mathrm{m}$ \\
\hline $\begin{array}{l}\text { Sample volume and running } \\
\text { buffer }\end{array}$ & $\begin{array}{l}\text { Sample volume }=60-80 \mu \mathrm{l} \\
\text { Sample running buffer }=10 \mathrm{mM} \\
\text { phosphate buffer, pH } 7.2 \text { with } \\
\text { SDS }\end{array}$ \\
\hline $\begin{array}{l}\text { Concentration of anti-CPV-tVP2 } \\
\text { rabbit pAbs on test line }(1,2 \text { and } \\
5 \mathrm{mg} / \mathrm{ml})\end{array}$ & $2 \mathrm{mg} / \mathrm{ml}$ \\
\hline $\begin{array}{l}\text { Concentration of goat anti-mouse } \\
\text { pAbs on control line (1,2 and } 5 \\
\mathrm{mg} / \mathrm{ml})\end{array}$ & $1 \mathrm{mg} / \mathrm{ml}$ \\
\hline $\begin{array}{l}\text { Completion time (5,10 and } 20 \\
\text { min) }\end{array}$ & $10 \min$ \\
\hline
\end{tabular}




\section{Preparation of an $\mathrm{mAb} / \mathrm{mAb}$-based lateral flow immunochromatographic test strip}

The procedure described in the previous section was essentially followed, except instead of anti-CPV-tVP2 pAb, commercially procured anti-CPV mAb (VMRD, USA) was used as the capture antibody $(1 \mathrm{mg} / \mathrm{ml})$ for coating on the test line.

\section{Assay procedure}

Upon interaction of CPV antigen with mAb-gold conjugate, a CPV-mAb-gold complex formed, which migrated onto the nitrocellulose membrane and subsequently reacted with immobilized capture antibodies (anti-CPV-tVP2 pAbs or anti CPV mAbs) on the test line, whereas unbound anti-CPV monoclonal gold conjugate ran over the test line and then reacted with the goat anti-mouse antibody at the control line to form a second visible purple-red band. The sample was considered positive if two distinct purple-red lines appeared, one in the test region and the other in the control region, negative when no line appeared in the test region, and invalid if the control line failed to appear.

\section{Estimation of the sensitivity and specificity of the IC strip test}

The analytical sensitivity of the $\mathrm{mAb} / \mathrm{pAb}$ and $\mathrm{mAb} / \mathrm{mAb}$ based test strips were determined using a serially diluted live attenuated strain of CPV (TN-4; NCBI GenBank accession number KX219741) with $10^{7} \mathrm{TCID}_{50} / \mathrm{ml}$. The standard CPV and known A-72-cell-adapted CPV-2a and CPV-2b isolate (CPV-2a isolate BE-1, NCBI GenBank accession number $\mathrm{KJ} 364524$; CPV-2b isolate PALAM1CPV2b/CAD/2010, NCBI GenBank accession number KX181847.1) were tested as positive controls, whereas a mock-infected A-72 cell culture supernatant, fecal swabs from healthy dogs showing no apparent clinical signs of canine parvoviral disease, and phosphate-buffered saline were used as negative controls.

The cross-reactivity of the IC test with other pathogens was tested using standard antigens from canine adenovirus 1 (CAV-1), canine distemper (CD) virus vaccine strain, Salmonella Typhimurium, Clostridium perfringens type A and Leptospira canicola (vaccine antigen) on test strips. The specific bacterial and viral agents were obtained from the institute repository. To determine the stability of the IC strips, assembled strips from the one batch were stored at $4{ }^{\circ} \mathrm{C}$ and tested repeatedly with known CPV-positive and negative samples every 15 days for a period of 3 months.

To determine the performance of IC test with clinical samples, 97 fecal swabs were tested simultaneously using the IC test, an HA test, and a commercial Rapid CPV Ag Test Kit (Bionote, Korea). The relative sensitivity and specificity of test were determined using Medcalc epidemiological calculator software at a confidence level of $95 \%$. Kappa statistics were used to determine the strength of the agreement of the results between the two tests.

\section{Results}

\section{Expression of recombinant tVP2 protein and generation of anti-CPV-tVP2 rabbit pAbs}

Optimal expression of both proteins was observed at $8 \mathrm{~h}$ post-induction using $1 \mathrm{mM}$ IPTG at $37^{\circ} \mathrm{C}$. A fair level of purification was achieved for both $6 \times$ His-tagged recombinant CPV-tVP2 proteins using Ni-NTA resin, as indicated by $12 \%$ SDS-PAGE analysis. The observed molecular weight was close to the predicted molecular weight of 51 $\mathrm{kDa}$ and $54 \mathrm{kDa}$ for the $\mathrm{N}$ and $\mathrm{C}$ terminal protein, respectively, as indicated by Western blot analysis using CPVpositive sera from vaccinated animals (Fig. 1).

A dot-blot showed appreciable reactivity of rabbit antiCPV-tVP2 polyclonal serum against the CPV-tVP2 protein and the A-72-adapted virus (Fig. 1). A fairly high concentration $(2.5 \mathrm{mg} / \mathrm{ml})$ of total $\mathrm{IgG}$ fraction was obtained by purification from the rabbit hyperimmune serum. The purity of the IgG was sufficiently high, as determined by SDS-PAGE analysis (data not shown).

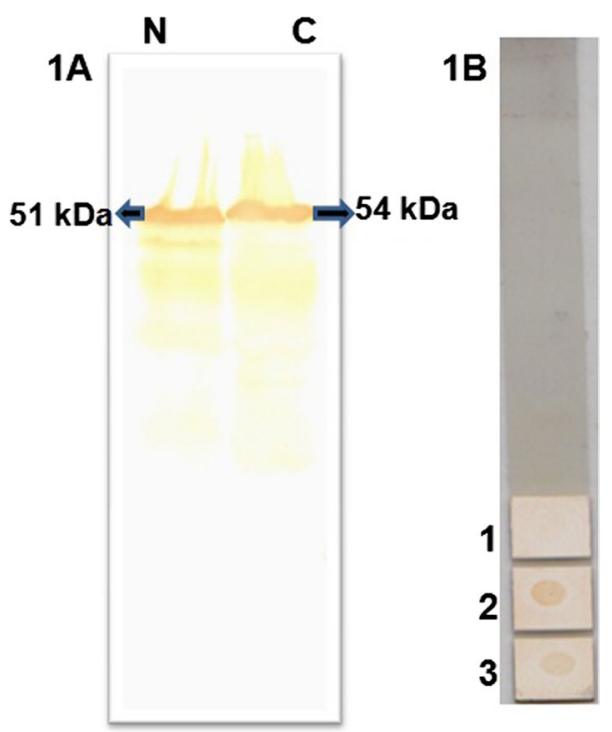

Fig. 1 (A) Western blot image showing the reactivity of $\mathrm{N}$ - and $\mathrm{C}$-region tVP2 proteins against a positive serum from a vaccinated dog. (B) Dot-blot showing the reactivity of PBS (1), CPV-tVP2 protein (2) and A-72-grown CPV (3) against rabbit anti-CPV-tVP2 polyclonal serum 


\section{Preparation of colloidal gold conjugate}

Based on findings of UV-Vis absorbance and flocculation assays, it was observed that GNPs at $\mathrm{pH} 8.0$ adsorbed with anti-CPV mAb ranging in concentration from 10 to $20 \mu \mathrm{g} / \mathrm{ml}$ provided satisfactory conjugation (Fig. 2). Optimal coupling of mAbs on the GNP surface was observed in the form of an increase in the absorbance peak and the average diameter of the GNPs detected by UV-Vis measurement and DLS/particle size analysis, respectively. The UV-Vis measurement of GNPs before and after conjugation with $\mathrm{mAbs}$ indicated a marginal shift $(5 \mathrm{~nm})$ in the absorbance peak from its $\lambda_{\max }$ value $(526 \mathrm{~nm})$ (Fig. 3). Likewise, DLS findings revealed an increase in the average diameter of GNPs from 36.6 to 48.5 $\mathrm{nm}$ following $\mathrm{mAb}$ addition, suggestive of antibody coupling (Fig. 3). TEM imaging revealed that the GNPs coupled with $\mathrm{mAb}$ had halos around the gold particles due to the adsorption of antibodies (Fig. 3). Additionally, it was observed that the colloidal gold conjugate displayed immune reactivity to a standard CPV antigen (Fig. 3).

\section{Evaluation of IC test performance in detection of clinical samples}

The strip test was validated by testing fecal samples collected from pups suspected of CPV infection in comparison with the HA test and a commercial CPV Ag kit (Fig. 4). Out of a total of 97 fecal samples examined, 34, 41, 29 and 37 samples gave positive results in the HA test, the commercial $\mathrm{CPV} \mathrm{Ag}$ test, and mAb-pAb- and mAb-mAb-based IC tests, respectively. The relative sensitivity/specificity of the new strip test based on mAb-pAb in comparison to HA and the commercial IC kit was recorded as $71 \% / 92 \%$ and $71 \% / 100 \%$, respectively, with substantial agreement $(\kappa=0.736-0.757)$ (Table 2). However, the relative sensitivity and specificity of the new IC test based on mAb-mAb combination was $82 \% / 87 \%$ (substantial agreement; $\kappa=0.687$ ) and 90\%/98\% (almost perfect agreement; $\kappa=0.892$ ) in relation to the HA and commercial strip test, respectively (Table 3 ). In addition, the results of IC test based on either combination ( $\mathrm{mAb}$ or pAb as capture antibodies) and the commercial IC test were almost uniformly positive, with fecal samples showing HA titers greater than 256 (Table 4).

\section{Discussion}

Canine parvovirus is the number one cause of viral enteritis in dogs and is responsible for significant morbidity and mortality [17]. An accurate and rapid diagnosis of the virus at very early stages of infection is pivotal in controlling the disease. The SNAP Parvo Test (Idexx, USA) is used by clinicians worldwide as an in-house test for rapid detection of
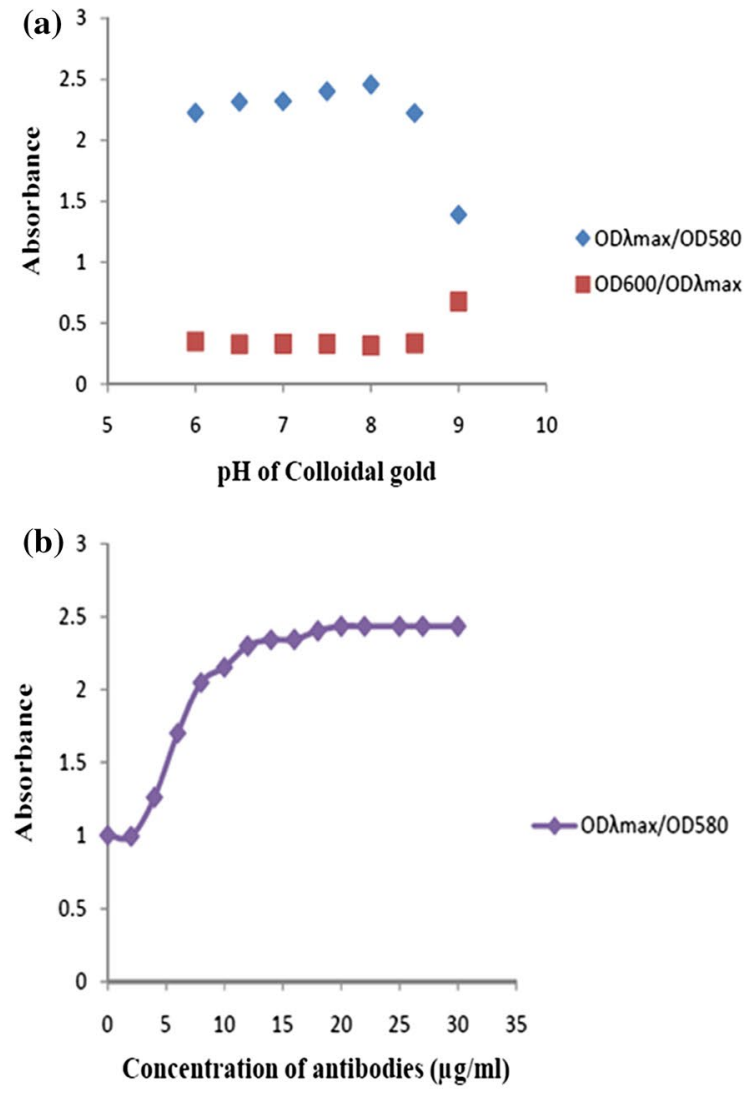

(c)

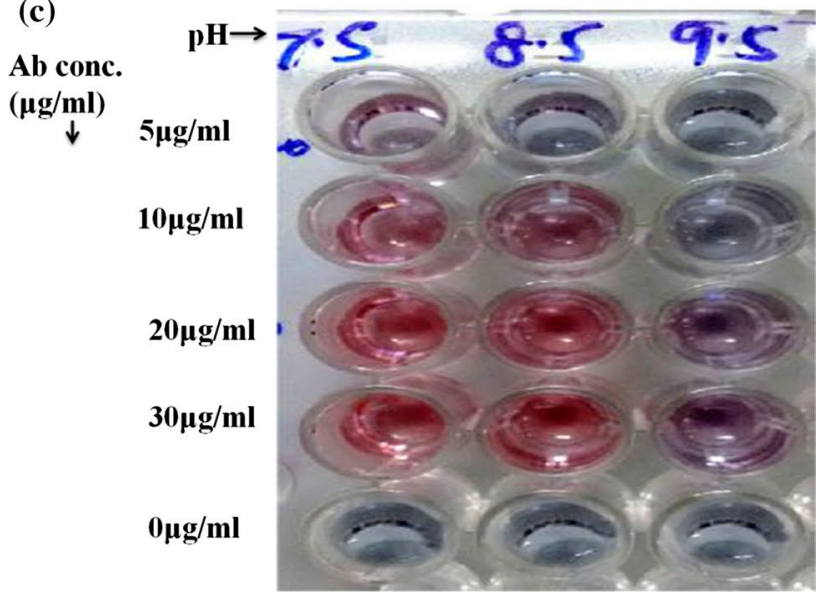

Fig. 2 (A) Determination of optimum $\mathrm{pH}$ for producing a stable gold conjugate. The image shows the SI and PI values of the colloidal gold conjugate at different $\mathrm{pH}$ values after addition of $10 \% \mathrm{NaCl}$. The colloidal GNPs were most stable and least polydisperse at pH 8.0. (B) Determination of the optimum concentration of mAbs for coupling of GNPs depicted by a curve showing the absorbance at $580 \mathrm{~nm}$ vs. the mAb concentration (SI). The image shows that the stability of the gold particles increased with increasing amounts of anti-CPV mAbs and remained constant after $20 \mu \mathrm{g} / \mathrm{ml}$. Hence, the optimal amount of mAbs required to stabilize the GNPs against $10 \% \mathrm{NaCl}$ is $20 \mu \mathrm{g} / \mathrm{ml}$. (C) Determination of the optimum $\mathrm{pH}$ and antibody concentration using a flocculation assay, i.e. visual recording of any color change in GNPs from red to blue/violet after addition of $10 \% \mathrm{NaCl}$. The image reveals that a $\mathrm{pH}$ range of 7.5-8.5 and an $\mathrm{mAb}$ concentration of $10-30 \mu \mathrm{g} / \mathrm{ml}$ may be sufficient for stability of the conjugate. Thus, the optimum $\mathrm{pH}$ and $\mathrm{mAb}$ concentration were chosen as 8.0 and $20 \mu \mathrm{g} / \mathrm{ml}$, respectively 
(a)

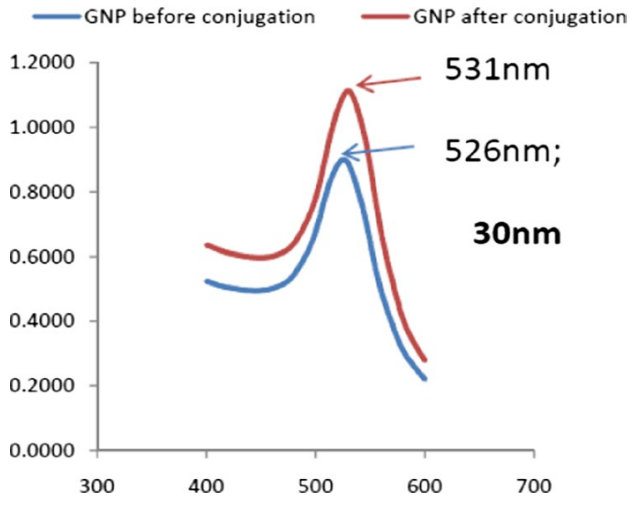

(b)

\begin{tabular}{|c|c|}
\hline GNPs Size & $30 \mathrm{~nm}$ \\
\hline Average diameter pre- conjugation & $36.6 \mathrm{~nm}$ \\
\hline Average diameter post-conjugation & $48.5 \mathrm{~nm}$ \\
\hline
\end{tabular}
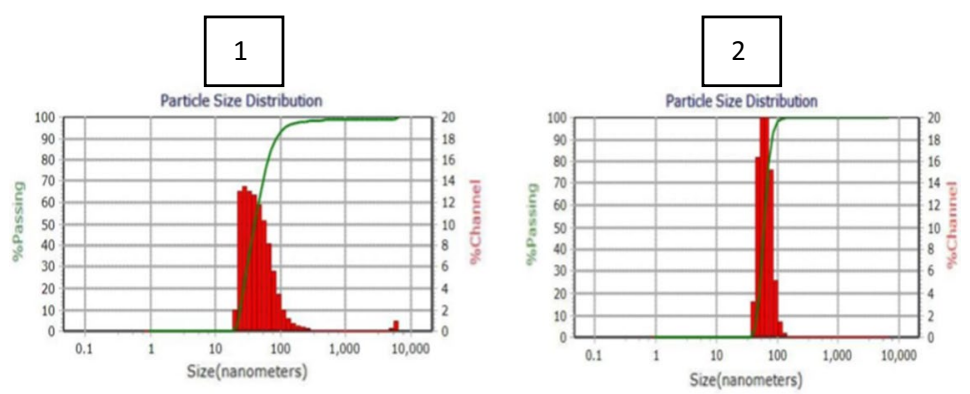

(c)

1

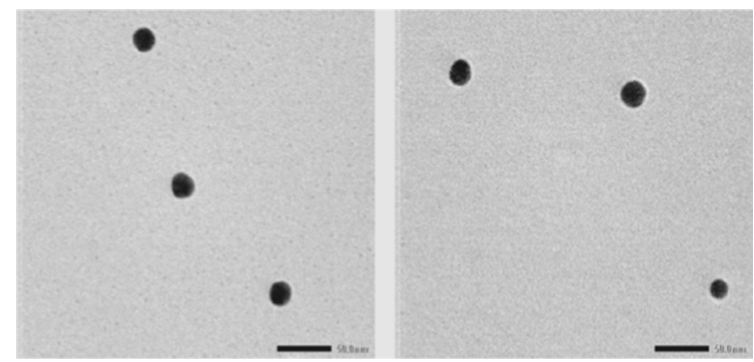

Fig. 3 (A) UV/Vis spectra of colloidal GNPs and the anti-CPV mAb-colloidal GNP conjugate, showing an increase in the absorbance wavelength of GNPs (526 to $531 \mathrm{~nm}$ ) after mAb coupling. Blue line, colloidal gold solution; red line, gold-mAb conjugate. (B) DLS spectrum of (1) colloidal GNPs and (2) anti-CPV mAb-gold conjugate visible in the form of an increase in the average diameter of (d)

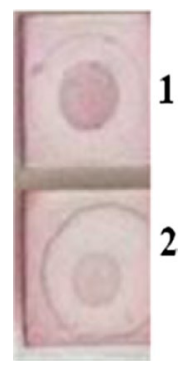

GNPs from 36.6 to $48.5 \mathrm{~nm}$ after mAb coupling. (C) TEM image of (1) colloidal GNPs and (2) anti CPV-mAb-gold conjugate visible in the form of a halo around gold particles, indicating the adsorption of mAbs on the GNPs. (D) Dot-blot showing the reactivity of prepared mAb-gold conjugate against (1) cell-culture adapted CPV and (2) commercial CPV vaccine antigen
Fig. 4 Images of IC test showing (A) no reactivity with either PBS or mock-infected DMEM medium, (B) positivity in the form of the appearance of two visible red color bands at the test and control lines, detected by employing mAb/pAb and (C) $\mathrm{mAb} / \mathrm{mAb}$ at the test and control line in prototype IC tests. (SP, sample pad; CP, conjugate pad; AP, absorbent pad; T, test line $\mathrm{C}$, control line)
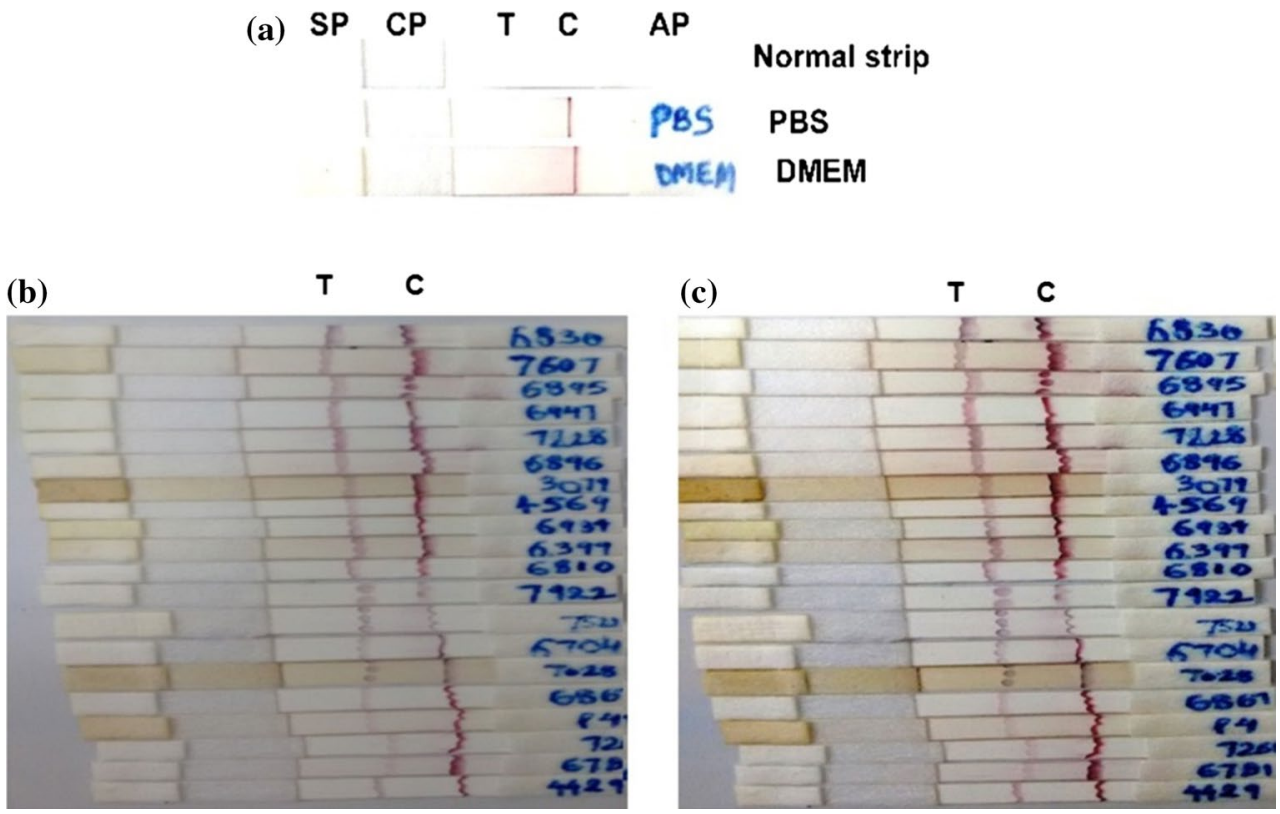
Table 2 Determination of the relative sensitivity and specificity of the new prototype strip test (mAbs/ pAbs) in comparison to HA and commercial antigen kit

\begin{tabular}{|c|c|c|c|c|c|c|c|}
\hline \multirow{2}{*}{$\begin{array}{l}\text { Prototype strip test (pAb as } \\
\text { capture antibodies) vs HA } \\
\text { test }\end{array}$} & \multicolumn{2}{|c|}{ HA test } & \multirow[t]{2}{*}{ Total } & \multirow{2}{*}{$\begin{array}{l}\text { Prototype strip test (pAb as } \\
\text { capture antibodies) vs commer- } \\
\text { cial kit }\end{array}$} & \multicolumn{2}{|c|}{$\begin{array}{l}\text { Commer- } \\
\text { cial kit }\end{array}$} & \multirow[t]{2}{*}{ Total } \\
\hline & + & - & & & + & - & \\
\hline \multicolumn{4}{|l|}{ Prototype strip test } & \multicolumn{3}{|l|}{ Prototype strip test } & \\
\hline+ & 24 & 05 & 29 & + & 29 & 0 & 29 \\
\hline- & 10 & 58 & 68 & - & 12 & 56 & 68 \\
\hline Total & 34 & 63 & $\mathrm{n}=97$ & Total & 41 & 56 & $\mathrm{n}=97$ \\
\hline \multicolumn{4}{|c|}{$\begin{array}{l}\text { Sensitivity }=71 \%(95 \% \text { CI: 52.52-84.90\%) } \\
\text { Specificity }=92 \% \text { (95\% CI: 82.44-97.37\%) }\end{array}$} & \multicolumn{3}{|c|}{$\begin{array}{l}\text { Sensitivity }=71 \%(95 \% \text { CI: } 54.46-83.87 \%) \\
\text { Specificity }=100 \% \text { (95\%CI: 93.62-100.00\%) } \\
\text { Kappa value }=0.736 \text { (Substantial agreement) }\end{array}$} & \\
\hline
\end{tabular}

Table 3 Determination of the relative sensitivity and specificity of the new prototype strip test (mAb/ $\mathrm{mAb}$ ) in comparison to HA and commercial antigen kit

\begin{tabular}{|c|c|c|c|c|c|c|c|}
\hline \multirow{2}{*}{$\begin{array}{l}\text { Prototype strip test (mAb as } \\
\text { capture antibodies) vs HA } \\
\text { test }\end{array}$} & \multicolumn{2}{|c|}{ HA test } & \multirow[t]{2}{*}{ Total } & \multirow{2}{*}{$\begin{array}{l}\text { Prototype strip test (mAb as } \\
\text { capture antibodies) vs commer- } \\
\text { cial kit }\end{array}$} & \multicolumn{2}{|c|}{$\begin{array}{l}\text { Commer- } \\
\text { cial kit }\end{array}$} & \multirow[t]{2}{*}{ Total } \\
\hline & + & - & & & + & - & \\
\hline \multicolumn{4}{|l|}{ Prototype strip test } & \multicolumn{4}{|l|}{ Prototype strip test } \\
\hline+ & 28 & 08 & 36 & + & 36 & 01 & 37 \\
\hline- & 06 & 55 & 61 & - & 04 & 56 & 60 \\
\hline Total & 34 & 63 & $\mathrm{n}=97$ & Total & 40 & 57 & $\mathrm{n}=97$ \\
\hline \multicolumn{4}{|c|}{$\begin{array}{l}\text { Sensitivity }=82 \%(95 \% \text { CI:65.47\%-93.24\%) } \\
\text { Specificity }=87 \% \text { (95\% CI: } 76.50 \%-94.35 \%) \\
\text { Kappa value }=0.687 \text { (Substantial agreement) }\end{array}$} & \multicolumn{4}{|c|}{$\begin{array}{l}\text { Sensitivity }=90 \%(95 \% \text { CI: } 76.34 \%-97.21 \%) \\
\text { Specificity }=98 \% \text { (95\% CI: } 90.61 \%-99.96 \%) \\
\text { Kappa value }=0.892 \text { (Almost perfect agreement) }\end{array}$} \\
\hline
\end{tabular}

Table 4 Number of fecal samples screened by prototype and commercial IC test displaying positive results with their respective HA titers

\begin{tabular}{llll}
\hline HA Titer & $\begin{array}{l}\text { Prototype strip } \\
\text { test (mAb/pAb) }\end{array}$ & $\begin{array}{l}\text { Prototype strip } \\
\text { test (mAb/mAb) }\end{array}$ & $\begin{array}{l}\text { Commercial } \\
\text { Rapid CPV Ag } \\
\text { kit }\end{array}$ \\
\hline$<32$ & 5 & 8 & 12 \\
32 & 2 & 2 & 5 \\
64 & 0 & 2 & 2 \\
128 & 1 & 2 & 2 \\
256 & 3 & 3 & 3 \\
$\geq 512$ & 18 & 20 & 17 \\
\hline
\end{tabular}

canine parvovirus. This is a fecal CPV antigen test based on enzyme-linked immunosorbent assay (ELISA) technology [18]. Although it is very specific, its sensitivity has been reported to be widely variable, from as low as $18.4 \%$ [19] to as high as $81.8 \%$ [20]. With the development of colloidalgold-based rapid IC assays, testing of samples under field conditions with a fair level of confidence is now possible. However, because of the high cost, the diagnosis of CPV infection using existing IC tests is not affordable, especially in developing countries like India, for testing a large population of dogs. In the existing setting, two mAbs (as detector and capture antibodies) targeting different epitopes of CPV are required for high sensitivity of the IC assays, which also increases the cost per test $[19,21]$. However, antibodyinduced conformational changes of epitopes might also limit the sensitivity of IC tests utilizing two heterologous mAbs as capture and detector antibodies [12]. Use of the same mAb as both the capture and detector antibody in the sandwich format can potentially reduce the cost but simultaneously may decrease the sensitivity of the IC assay.

It is known that in comparison to mAbs, pAbs are less expensive to generate (one-fifth the cost of $\mathrm{mAbs}$ ) and can be produced much more rapidly (the turnaround time is less than half of that for mAbs) with little technical skill [22]. Thus, it was hypothesized that inclusion of pAbs, which is more economical and can detect multiple epitopes simultaneously, may replace at least one mAb in the sandwich format of an IC test and thereby reduce the overall cost. As preparation of a colloid gold conjugate employing pAbs for use as the detector is not desirable because of their heterogeneity, in the present work, a commercial anti-CPV mAb was used for conjugate preparation, and rabbit anti-CPVtVP2 pAbs were employed to coat the test line. One existing commercial IC kit for rapid detection of canine parvovirus (Witness Parvo; Synbiotic, USA) also uses a CPV-specific $\mathrm{mAb}$ for detection and a $\mathrm{pAb}$ for capture. There are also several published reports indicating the successful use of pAbs as capture antibodies in IC assays [23].

In most IC assays, the analyte (pathogen) is detected based on the accumulation of GNPs at the immobilized 
capture antibody site using sandwich-type immunoreactions $[24,25]$. The key factors influencing the analyte detection limit or sensitivity of the sandwich IC assay include the size of the GNPs and the conjugation procedure, which mainly includes buffer $\mathrm{pH}$ and antibody concentration.

The available literature generally supports the use of GNPs in the range of 20-40 nm for preparation of the conjugate for IC tests $[24,26]$. In the present work, a conjugate prepared with 30-nm GNPs displayed sufficient stability and immune reactivity towards the CPV antigen (Fig. 3). The degree of stabilization of colloidal gold conjugate is directly proportional to the SI and inversely proportional to the PI [15]. The ideal $\mathrm{pH}$ and $\mathrm{mAb}$ concentration required for proper coverage of GNPs were determined on the basis of SI and PI values and further confirmed by flocculation assay, which indicated that a $\mathrm{pH}$ ranging from 7.5 to 8.5 (average, 8.0) with an mAb concentration of $10-30 \mu \mathrm{g} / \mathrm{ml}$ was sufficient to prevent a color change from red to violet following addition of $10 \% \mathrm{NaCl}$ (Fig. 2). From the flocculation experiment, the minimum protective amount (MPA) of $\mathrm{mAb}$ required to prevent the color change in GNPs from red to blue/violet was found to be $10 \mu \mathrm{g} / \mathrm{ml}$ (Fig. 2); however, the optimum amount of antibody needed for proper coverage of the GNP surface was determined on the basis of the stability index, which corresponds to $20 \mu \mathrm{g} / \mathrm{ml}$ (Fig. 2). This is in agreement with previous reports in which it was recommended to use a twofold excess of antibody for proper coverage of the GNP surface [24].

The optimal coverage of GNPs was also ensured by using several established methods, which revealed an increase in wavelength of the absorbance peak ( 526 to $531 \mathrm{~nm}$ ) and the average diameter of GNPs (36.6 to $48.5 \mathrm{~nm}$ ) as well as the appearance of a halo effect in TEM images after addition of mAbs (Fig. 3). This is suggestive of antibody coupling on GNPs and consistent with an earlier report [16].

Truncated recombinant proteins have been shown to be applicable for use in diagnosis of many infections [27, 28]. Therefore, in the current study, we used two CPV-tVP2 proteins covering almost the full length of the VP2 capsid protein of CPV as a source of antigen to raise rabbit pAbs, and to the best of our knowledge, this is the first IC assay in which CPV-tVP2-specific pAbs are used as capture antibodies for detection of CPV. The VP2 capsid protein contains most of the immunogenic epitopes near the N-terminal region [29]. However, to cover an almost full-length VP2 gene, two almost equal fragments $(\mathrm{N}=760 \mathrm{bp}$ and $\mathrm{C}=891$ bp) were selected for ease of expression.

The minimum detection limit recorded with the newly developed $\mathrm{mAb} / \mathrm{pAb}$-based prototype IC assay was $6.6 \times$ $10^{5} \mathrm{TCID}_{50} / \mathrm{ml}$, a level that is marginally higher than the value $\left(3.13 \times 10^{5} \mathrm{TCID}_{50} / \mathrm{ml}\right)$ reported for the commercial IC based kit to detect CPV in fecal samples. This could be acceptable, considering its economical benefit in addition to its ability to detect CPV, especially at early stages of disease when viral loads are typically high $\left(>10^{8} \mathrm{CCID}_{50}\right)$. The CPV standard and its antigenic variants (CPV-2a and CPV2b) gave positive results within 10 min with the new IC test, while other canine enteric pathogens tested in present study gave negative results, indicating the specificity of the strip test. The IC test results were reproducible when testing positive and negative specimens after up to 3 months of storage at $4{ }^{\circ} \mathrm{C}$, which is consistent with an earlier report in which antibody colloidal gold conjugate was reported to be stable for at least 2 months at $4{ }^{\circ} \mathrm{C}$ [30]. Previous studies have already shown that in-clinic IC tests rarely detect the attenuated parvovirus vaccine strain, due to the very low level of vaccine virus shed in the feces, providing the user a level of confidence that a positive test result with these tests always indicates the presence of wild-type pathogenic virus regardless of recent vaccination [31]. However, these in-clinic tests, including our newly developed one, do not differentiate between the wild and vaccine strains of $\mathrm{CPV}-2$.

Because there is no gold standard assay to detect CPV in fecal samples, the prototype IC test was compared separately with the HA test and a commercial CPV antigen kit using a panel of 97 clinical samples from animals suspected of having a CPV infection (Fig. 4). The relative sensitivity/ specificity of the $\mathrm{mAb} / \mathrm{pAb}$-based strip test in comparison to the HA and commercial IC kit was 71\%/92\% and 71\%/100\%, respectively. This is in accordance with earlier findings which revealed that HA test is slightly more sensitive but less specific than IC tests [9]. Similar findings have also been reported for a commercial IC kit (Witness Parvo; Synbiotic, USA), where the relative sensitivity and specificity in comparison to the HA test was $63 \%$ and $93 \%$, respectively [32]. The lower sensitivity observed with prototype IC test may be due to the nonspecific hemagglutination in fecal samples with HA titers up to 512. It is not essential for the IC test to be more sensitive than the HA test, as both of these fieldbased tests have their distinct merits.

Interestingly, with use of $\mathrm{pAb}$ as capture antibodies, a very high level of specificity was observed in comparison to the HA and commercially available kit. This finding is supported by a previous report that indicated that pAbs frequently have better specificity than $\mathrm{mAbs}$ because they are produced by a large number of B cell clones, each generating antibodies to a specific epitope [22]. There was substantial agreement ( $\kappa=0.736-0.757$ ) observed between the new IC test and the HA and commercial kit results (Table 2). Hence, the above results confirmed that the $\mathrm{mAb} / \mathrm{pAb}$-based IC test has similar specificity but lower sensitivity than the HA and commercial kits (Table 2). It was also demonstrated that $\mathrm{pAb}$ reactive with $\mathrm{CPV}$ can be produced economically by using recombinant truncated structural proteins. However, as reported by Turiso et al. [29], the use of recombinant proteins in their native form 
can generate antibodies with high affinity, which will be, evaluated in future studies.

Comparing the results obtained with the $\mathrm{mAb} / \mathrm{mAb}$-based prototype strip test in relation to the HA test revealed high sensitivity (82\%) and moderate specificity (87\%), with substantial agreement and high sensitivity/specificity (90/98\%) (almost perfect agreement) in relation to the commercial kit (Table 3). The use of two different anti-CPV mAbs as detector and capture antibodies in new prototype strip test gave almost identical results (minimum detection limit, $3.12 \times 10^{5} \mathrm{TCID}_{50} /$ $\mathrm{ml})$ in relation to the commercial CPV antigen kit $\left(3.13 \times 10^{5}\right.$ $\mathrm{TCID}_{50} / \mathrm{ml}$ ). Additionally, it appeared that a high viral load (HA titer $\geq 256$ ) in clinical samples was needed to capture the gold-mAb-CPV complexes, which is evident from the correlation between HA titers with IC positivity and is consistent with earlier findings [32] (Table 4).

The present study provides an important proof of concept for development of an economical mAb/pAb-based IC test for on-site diagnosis of parvoviral enteritis in dogs with very high specificity. An $\mathrm{mAb} / \mathrm{mAb}$-based variation of this assay showed very high sensitivity and comparable specificity. The availability of both the assays will provide flexibility to choose either high sensitivity or specificity as required. This prototype test (mAb/pAb) may present the new choices for CPV diagnosis, considering its economical benefit and high specificity. Consequently, in cases where the IC result is negative but the index of suspicion is high, it is recommended to send the sample for further laboratory examination using highly sensitive molecular assays. Given the ongoing need for a simple, and economical point-of-care test for CPV diagnosis, it is warranted to screen a larger number of clinical samples using this prototype test for further validation.

Acknowledgements We wish to acknowledge the Director, ICARIndian Veterinary Research Institute, Izatnagar, for providing necessary facilities to carry out this work.

\section{Compliance with ethical standards}

Funding This study was funded in part by the Indian Council of Agricultural Research - Indian Veterinary Research Institute.

\section{Conflict of interest The authors declare no conflict of interest.}

Ethical approval All applicable guidelines for the care and use of animals were followed (Institutional Animal Ethical Committee approval Lr. no. (F.1-53/2012-13-J.D.Res dated 05.10.2013). The consent of the animal owners was sought for collecting rectal swabs from dogs.

\section{References}

1. Appel MJG, Scott FW, Carmichael LE (1979) Isolation and immunization studies of a canine parvo-like virus from dogs with hemorrhagic enteritis. Vet Rec 105:156-159
2. Parrish CR (1999) Host range relationships and the evolution of canine parvovirus. Vet Microbiol 69:29-40

3. Cotmore SF, Tattersall P (2007) Parvoviral host range and cell entry mechanisms. Adv Virus Res 70:183-232

4. Hueffer K, Parker JS, Weichert WS, Geisel RE, Sgro JY, Parrish CR (2003) The natural host range shift and subsequent evolution of canine parvovirus resulted from virus-specific binding to the canine transferrin receptor. J Virol 77:1718-1726

5. Hoelzer K, Parrish CR (2010) The emergence of parvoviruses of carnivores. Vet Res 41:39

6. Chander V, Chakravarti S, Gupta V, Nandi S, Singh M, Badasara SK, Sharma C, Mittal M, Dandapat S, Gupta VK (2016) Multiplex Amplification Refractory Mutation System PCR (ARMSPCR) provides sequencing independent typing of canine parvovirus. Inf Gent Evol 46:59-64

7. Thomas J, Singh M, Goswami TK, Verma S (2017) Phylogenetic analysis of partial VP2 gene of canine parvovirus-2 from Northern region of India. Vet arhiv 87(1):57-66

8. Mochizuki M, Harasawa R, Nakatani H (1993) Antigenic and genomic variabilities among recently prevalent parvoviruses of canine and feline origin in Japan. Vet Microbiol 38:1-10

9. Desario C, Decaro N, Campolo M, Cavalli A, Cirone F, Elia G, Martella V, Lorusso E, Camero M, Buonavoglia C (2005) Canine parvovirus infection: which diagnostic test for virus? J Virol Meth 126:179-185

10. Decaro N, Buonavoglia C (2012) Canine parvovirus: A review of epidemiological and diagnostic aspects, with emphasis on type 2c. Vet Microbiol 155:1-12

11. Kantere MC, Athanasiou LV, Spyrou V, Kyriakis CS, Kontos V, Chatzopoulos DC, Tsokana CN, Billinis C (2015) Diagnostic performance of a rapid in clinic test for the detection of Canine Parvovirus under different storage conditions and vaccination status. J Virol Methods 215:52-55

12. Cepica A, Yason C, Ralling G (1990) The use of ELISA for detection of the antibody induced conformational change in a viral protein and its intermolecular spread. J Virol Meth 28:1-14

13. Thomas J, Singh M, Goswami TK, Verma S, Badasara SK (2014) Polymerase chain reaction based epidemiological investigation of canine parvoviral disease in dogs at Bareilly region. Vet World 7:929-932

14. Thomas J, Singh M, Goswami TK, Glora P, Chakravarti S, Chander V, Upmanyu V, Verma S, Sharma C, Mahendran K (2017) Determination of immune status in dogs against CPV-2 by recombinant protein based latex agglutination test. Biologicals 49:51-56

15. Nara S, Tripathi V, Singh H, Shrivastav GT (2010) Colloidal gold probe based rapid immunochromatographic strip assay for cortisol. Anal Chim Acta 682:66-71

16. Thobhani S, Attree S, Boyd R, Kumarswami N, Noble J, Szymanski M, Porter RA (2010) Bioconjugation and characterisation of gold colloid-labelled proteins. J Immunol Methods 356:60-69

17. Kapil S (1995) Laboratory diagnosis of canine viral enteritis. Curr Vet Ther 12:697-701

18. Proksch AL, Unterer S, Speck S, Truyen U, Hartmann K (2015) Influence of clinical and laboratory variables on faecal antigen ELISA results in dogs with canine parvovirus infection. Vet $\mathbf{J}$ 204:304-308

19. Schmitz S, Coenen C, Konig M, Thiel HJ, Neiger R (2009) Comparison of three rapid commercial canine parvovirus antigen detection tests with electron microscopy and polymerase chain reaction. J Vet Diag Invest 21:344-345

20. Markovich JE, Stucker KM, Carr AH, Harbison CE, Scarlett JM, Parrish CR (2012) Effects of canine parvovirus strain variations on diagnostic test results and clinical management of enteritis in dogs. J Am Vet Med Assoc 241:66-72 
21. Greene CE, Decaro N (2012) Canine viral enteritis. Infectious diseases of the dog and cat. 4th edn. Saunders Elsevier, St. Louis, pp 67-76

22. Lipman NS, Jackson LR, Trudel LJ, Weis-Garcia F (2005) Monoclonal versus polyclonal antibodies: distinguishing characteristics, applications, and information resources. ILAR J 46:258-268

23. Phan JC, Pettitt J, George JS, Fakoli LS III, Taweh FM, Bateman SL, Bennett RS, Norris SL, Spinnler DA, Pimentel G, Sahr PK, Bolay FK, Schoepp RJ (2016) Lateral flow immunoassays for Ebola virus disease detection in Liberia. J Inf Dis 214:S222-S228

24. Safenkova I, Zherdev A, Dzantiev B (2012) Factors influencing the detection limit of the lateral-flow sandwich immunoassay: a case study with potato virus X. Anal Bioanal Chem 403:1595-1605

25. Kang K, Chen L, Zhao X, Qin C, Zhan Z, Wang J, Li W, Dzakah EE, Huang W, Shu Y, Jiang T, Cao W, Xie M, Luo X, Tang S (2014) Development of rapid immunochromatographic test for hemagglutinin antigen of $\mathrm{H} 7$ subtype in patients infected with novel avian influenza A (H7N9) virus. PLoS One 9(3):92306

26. Yang M, Goolia M, Wanhong BH, Clavijo A (2013) Development of a quick and simple detection methodology for foot-and- mouth disease virus serotypes $\mathrm{O}, \mathrm{A}$ and Asia 1 using a generic rapid assay device. Virol J 10:125

27. Boonchit S, Xuan X, Yokoyama N, Goff WL, Waghela SD, Wagner G, Igarashi I (2004) Improved Enzyme-Linked
Immunosorbent Assay using C-terminal truncated recombinant antigens of Babesia bovis rhoptry associated protein-1 for detection of specific antibodies. J Clin Microbiol 42:1601-1604

28. Pathak KB, Biswas SK, Tembhurne PA, Hosamani M, Bhanuprakash V, Prasad G, Mondal B (2008) Prokaryotic expression of truncated VP7 of bluetongue virus (BTV) and reactivity of the purified recombinant protein with all BTV type-specific sera. $\mathrm{J}$ Virol Methods 152:6-12

29. Turiso JAL, Cortés E, Ranz A, García J, Sanz A, Vela C, Casal JI (1991) Fine mapping of canine parvovirus B cell epitopes. J Gen Virol 72:2445-2456

30. Saleh M, Soliman H, Haenen O, El-Matbouli M (2011) Antibodycoated gold nanoparticles immunoassay for direct detection of Aeromonas salmonicida in fish tissues. J Fish Dis 34:845-852

31. Decaro N, Crescenzo G, Desario C, Cavalli A, Losurdo M, Colaianni ML, Ventrella G, Rizzi S, Aulicino S, Lucente MS, Buonavoglia C (2014) Long-term viremia and fecal shedding in pups after modified-live canine parvovirus vaccination. Vaccine 32:3850-3853

32. Lacheretz A, Laperrousaz C, Kodjo A, Brajon N, Crevat D, Gulllossou S (2007) Diagnosis of canine parvovirus rapid immunomigration on a membrane. Vet Rec 152:48-50 